\title{
Platonism, Alienation, and Negativity
}

\author{
David Ingram ${ }^{1}$
}

Received: 15 April 2015/Accepted: 23 November 2015/Published online: 14 December 2015

(C) The Author(s) 2015. This article is published with open access at Springerlink.com

\begin{abstract}
A platonic theory of possibility states that truths about what's possible are determined by facts about properties not being instantiated (or being 'uninstantiated'). Recently, Matthew Tugby has argued in favour of this sort of theory, arguing that adopting a platonic theory of possibility allows us to solve a paradox concerning alien properties: properties that might have been instantiated, but aren't actually. In this paper, I raise a worry for Tugby's proposal (and the platonic theory, more generally) - that it commits us to negative facts playing an important truthmaking role-and offer a strategy to avoid the objectionable negativity.
\end{abstract}

\section{Introduction}

A platonic theory of possibility states that truths about what's actual are determined by facts about properties (universals) being instantiated whereas truths about what's merely possible are determined by facts about properties not being instantiated (or being 'uninstantiated'). ${ }^{1}$ Consider, e.g., Bigelow and Pargetter's (1990) illustrative statement of a platonic theory of possibility:

The actual world instantiates various properties. There are other ways the world could have been. If the world had been one of those ways, it would have instantiated different properties than the ones it does instantiate. Those other properties are uninstantiated. But, we claim, those uninstantiated properties do

\footnotetext{
${ }^{1}$ Platonists about possibility include Bigelow and Pargetter (1990), Forrest (1986), and Tugby (2015).

David Ingram

david.ingram@nottingham.ac.uk

1 Department of Philosophy, The University of Nottingham, Humanities Building, University

Park, Nottingham NG7 2RD, UK
} 
exist. They are what constitute the alternative possible ways the world could have been. (1990: 203)

Recently, Tugby (2015) has argued in favour of this sort of theory. Tugby argues that adopting a platonic theory of possibility allows us to solve a paradox concerning alien properties: properties that might have been instantiated, but aren't actually. In this paper, I raise a worry for Tugby's proposal (and the platonic theory, more generally) - that it commits us to negative facts playing an important truthmaking role-and offer a strategy to avoid the objectionable negativity.

\section{The Alien Paradox}

According to Tugby (2015: 30-31), the so-called 'alien paradox' comprises six apparently inconsistent propositions. These are:

1. It's true that instantiations of alien properties are metaphysically possible. (Possibility)

2. Truths about what's metaphysically possible have truth-makers. (Truth-maker)

3. Truth-makers determine their corresponding truths. (Determination)

4. All truth-makers exist. (Existence)

5. Everything that exists is actual. (Actualism)

6. Truths about alien properties aren't determined by what's actual. (Alienation)

Any inconsistency arising from the conjunction of the propositions is properly called a paradox because each of the propositions, (1)-(6), is independently plausible (2015: 30). The problem is: there's nothing actual that could function as a truth-maker for truths about possible alien property instantiations, and so we can't consistently maintain that such instantiations are possible. Given Alienation, what's required as truth-makers for truths about alien properties are non-actual entities. But, given Actualism, the only entities that exist (to be truth-makers) are actual entities. Tugby's solution is to deny Alienation and to endorse a platonic theory of possibility.

According to the platonic theory, truths about alien properties are determined by facts about what's actual, contrary to Alienation (2015: 33). The truth-making facts are that certain universals (actually) exist and that such universals aren't instantiated. These are facts about what's actual since the abstract universals (properties) that constitute the platonist's ontology are all actual, whether instantiated or uninstantiated (2015: 34). On the platonic theory, alien properties just are the uninstantiated universals; the relevant truth-makers for truths about possible alien instantiations are facts about properties that aren't instantiated but could have been (2015: 34-35). 


\section{Negativity}

Tugby's truth-making story rests on the distinction between 'a universal's being instantiated and being uninstantiated' (2015: 34). ${ }^{2}$ That is, truths about possible instantiations of alien properties are made true by facts about universals being uninstantiated. But, although Tugby doesn't acknowledge it, these are negative facts. The fact that some universal isn't instantiated (or $i s$ uninstantiated) is a fact about what isn't the case. ${ }^{3}$ The fact that some universal $\mathrm{F}$ is instantiated is a positive fact; its negation, that some universal $\mathrm{F}$ isn't instantiated, is a negative fact. Tugby is committed to facts of this latter sort as truth-makers on his account. (At least, a natural way to read Tugby's proposal involves a commitment to negative facts.) And platonists about possibility, insofar as they are committed to facts about properties being uninstantiated, more generally, are also committed to such negative ontology.

Typically, negative facts are considered to be unsuitable entities to play any truth-making role. Indeed, there's a general metaphysical suspicion of negative ontology, tout court. For instance, a classic statement of this uneasiness is due to Bertrand Russell:

There is implanted in the human breast an almost unquenchable desire to find some way of avoiding the admission that negative facts are as ultimate as those that are positive (1989: 287)

See also, amongst others:

...ontological commitment to absences would seem to be tantamount to a category mistake. ... absences are not themselves things, and so cannot be truthmakers. (Dodd, 2007: 388)

...can it really be a fact in the world that there is no hippopotamus in the room? This sounds like an absence of a fact, and an absence is nothing at all. (Mumford, 2007: 46)

The general objection to negative ontology is based on intuition and there's a deep dissatisfaction with postulating anything negative (e.g. negative facts, absences, limits, etc.). I don't propose to say anything new about why exactly we ought to be suspicious of negative facts, although I think we should be suspicious. Instead, I supplement Tugby's alien paradox with a seventh proposition:

7. Everything that exists is positive. (Positivity)

\footnotetext{
2 This is also part of platonism about possibility, generally. Recall, Bigelow and Pargetter's (1990) statement of the view: "uninstantiated properties do exist ... [and] are what constitute the alternative possible ways the world could have been' (1990: 203). Much the same is also true for Forrest (1986) who talks in terms of 'uninstantiated properties' (1986: 15).

3 If facts about what isn't the case determine truths about alien properties, we might wonder whether this reaffirms Alienation (truths about alien properties aren't determined by what's actual) at the expense of Actualism (everything that exists is actual). Not so. Facts about what isn't are negative facts and such facts, if they exist at all, exist actually.
} 
As above, an inconsistency arising from the conjunction of (1)-(7) is a paradox; the propositions are each independently plausible. Indeed, Positivity is highly plausible. Philosophers of realist and actualist inclinations, who accept that truths have actually existing truth-makers, i.e. the conjunction of Truth-maker (2), Existence (4), and Actualism (5), should be inclined to accept that everything that exists is positive, i.e. Positivity (7), as obviously true (cf. Molnar 2000; Dodd 2007; Mumford 2005, 2007; Tallant 2010; inter alia). Thus, Tugby's solution, denying Alienation, and endorsing a platonic theory, won't resolve this inconsistency since the truth-makers aren't positive.

Proponents of a platonic theory of possibility have two options for resolving the inconsistency in a way consistent with Tugby's original proposal. The first option is to deny Alienation and Positivity; the proposed truth-makers for possible alien property instantiations aren't positive, but that doesn't matter because not everything is positive. But Tugby should not take this route, by his own lights, since he advocates a conservative approach to the paradox, i.e. a solution that involves the least overall cost to intuition (2015: 33). (Tugby prefers a platonic solution, denying Alienation, to (e.g.) Lewis's (1986) view, denying Actualism, because it's less of an intuitive cost.) However, a solution that requires denying both Alienation and Positivity strikes me as much less conservative (than denying only Alienation, for instance). It's a greater cost to intuition to deny both propositions.

In what remains of Sect. 3, I examine two ways platonists about possibility could pursue this first option. Platonists might resolve the inconsistency by denying Alienation and Positivity by either (i) accepting negative facts, or (ii) accepting a 'totality fact' (cf. Armstrong 2004; inter alia). But, as I argue, both routes are unacceptable since both require accepting objectionable negative ontology. The second option for platonic theorists (to resolve the inconsistency conservatively) is to revise the proposed solution to avoid denying Positivity. To keep the truthmaking facts positive, I suggest that platonists adopt modal instantiation ties. (I outline this approach in Sect. 4.)

The most obvious way to pursue the first option is to accept the existence of all negative facts. That is, in addition to all the ordinary positive facts, e.g. that some universal $\mathrm{F}$ is instantiated, there are also negative facts, e.g. that some universal $\mathrm{G}$ isn't instantiated. On this view, for every way something isn't, there's a corresponding negative fact. But this is exactly the sort of approach that our philosophers of realist and actualist inclinations (Russell, Molnar, etc.) firmly oppose. It's a thoroughgoing denial of Positivity (everything that exists is positive), and involves admitting the existence of myriad negative facts, a significant ontological cost.

Another way that platonists about possibility might pursue the first option (denying Alienation and Positivity, to resolve the inconsistency) is to accept the existence of a 'totality fact'. David Armstrong proposes the existence of a totality fact: a higher-order fact that sums ('totals') all positive lower-order facts and determines that's all there is to reality (cf. Armstrong 1989: 92-97, 1997: 196-201, 2004: 54-82). ${ }^{4}$ Call this fact, '[TOTALity]'. Armstrong (2004) proposes [TOTALiTy] as

\footnotetext{
${ }^{4}$ See, also, Chalmers (1995: 85-86).
} 
the truth-maker for all negative truths, e.g. the proposition that Theaetetus is not flying or that there are no arctic penguins, rather than accepting a vast number of negative facts. As Armstrong puts it:

... a very great ontological economy has been effected. We get rid of the ontological nightmare of either a huge number of negative properties or a huge number of negative states of affairs, and substitute for them a single all state of affairs. It is a state of affairs (admittedly, a pretty large state of affairs, subsuming innumerable lesser allnesses), one that will serve as a truthmaker for the huge number of negative truths about Theaetetus among other particulars. (2004: 58)

Proponents of a platonic theory of possibility can plausibly build on this view. Suppose that all truths about possible instantiations of alien properties are made true by [тотаціту], which sums all the positive facts about the universals that exist and which universals are instantiated (and so determines which universals aren't instantiated). [тотАLiту] is a plausible truth-maker, given the platonic theory, since it implies all the relevant facts about when a universal isn't instantiated. Paraphrasing Armstrong, this also achieves ontological economy since the platonic theorist requires only one fact, [тотАLITY], rather than a vast number of negative facts.

But, of course, accepting the existence of a totality fact is a denial of Positivity, since [тотацiту] is a negative fact (cf. Molnar, 2000: 81-82; Armstrong 2004: 81-82). It's a fact which states "that's all there is" (or "there's nothing more," etc.) and so is properly described as negative. Regardless of the ontological economy, a solution involving a totality fact still requires denying both Alienation and Positivity. This solution strikes me as less conservative than any solution that requires denying only Alienation. (As before, it's a greater cost to intuition to deny both propositions.)

One might object that this rejection of a totality fact solution is too hasty, since there are positive aspects of [TOTALITY] (in addition to the negative, "that's all," aspect). ${ }^{5}$ One could argue that the positive aspect of the one (higher-order) totality fact is that, since it sums all (lower-order) positive facts, it's a fact about what there is, and so must be at least partially positive. Hence, accepting [TOTALITY] might not involve denying Positivity (everything that exists is positive), if we interpret the proposition as the more restricted claim that: "everything that exists is (at least partially) positive." And, at the very least, the totality fact solution seems in better standing, viz. denying Positivity, than a solution that requires myriad wholly negative facts. However, it's not clear to me that Positivity should be interpreted in this restricted way.

Given the general suspicion of negative ontology, described above, it seems Positivity should be understood as equivalent with a more definitive proposition, e.g.:

8. Nothing exists that is negative. (Anti-Negativity)

\footnotetext{
$\overline{5}$ I'm grateful to an anonymous reviewer for suggesting this line of objection.
} 
According to Positivity, so understood, everything that exists is wholly positive, since there's nothing that exists that's negative. This interpretation of Positivity strikes me as very plausible. If we motivate Positivity by appeal to the general suspicion of negativity, then we must accept Anti-Negativity (since all negativity is objectionable). Facts that are partially negative seem no better than facts that are wholly negative. Hence, both the negative fact and totality solutions are in equally bad standing, since both require platonists about possibility to deny Positivity (or Anti-Negativity).

There are further reasons to worry about the existence of [TотALITY]. For instance, as Schaffer (2008) neatly puts it:

Armstrong's totality fact, insofar as it conjoins all the first-order facts and then says that there are no more, further offends against the intuitions that the fundamental entities ought to be amenable to free recombination, and ought to be non-redundant. As to free recombination, none of the first-order facts can be altered without altering the totality fact, and the totality fact cannot be altered without altering at least some of the first-order facts. As to nonredundancy, the totality fact entails all the first-order facts. Indeed, once one posits the fundamental totality fact, it is mysterious why one would bother to posit any fundamental first-order facts whatsoever, since all of these are already entailed. The totality fact can go it alone. (2008: 12, fn. 4)

I won't discuss any such concerns in detail, since I think the denial of Positivity (or Anti-Negativity) is reason enough to worry. However, I think my solution, proposed in Sect. 4, in terms of modal instantiation doesn't offend against the same intuitions as the totality fact solution and so should be preferred, all things considered.

\section{Modal Instantiation Ties}

Consider two facts: the fact that something instantiates universal $F$ and the fact that nothing instantiates universal $G$. As noted, Tugby's truth-making story rests on this distinction between facts (i.e. $F$ is a property and $G$ is an alien property), and the distinction between a universal's being instantiated and being uninstantiated (2015: 34). But, even without the troublesome negativity, the fact that nothing instantiates $G$ doesn't seem like the right sort of fact to capture the metaphysical possibility of $G$ 's instantiation. ${ }^{6}$ Instead, consider two further facts: the fact that something actually instantiates $F$ and the fact that something possibly instantiates $G$. The fact that something possibly instantiates a universal does seem like the right sort of fact, but how might we capture this in a positive way?

I propose that truths about possible instantiations of alien properties are made true by facts involving particulars standing in a modal instantiation relation to universals. Ordinarily, we think of facts involving particulars standing in an

\footnotetext{
${ }^{6}$ I think the fact that a isn't $G$ (or, indeed, that nothing is $G$ ) doesn't seem like the right sort of aspect of reality to determine the truth of the proposition that a could have been $G$. But, perhaps, this view could be motivated by further consideration of what it is to be a universal, i.e. a repeatable entity that by its nature has the potential to be multiply instantiated (cf. Tugby 2015: 35). I explore this idea in more detail in Sect. 6.
} 
instantiation relation to universals, e.g. that $a$ is $F$, and that this is the only way to think about property-exemplification. But, recently, modifications of the instantiation relation have been adumbrated. ${ }^{7}$ McKinnon and Bigelow (2012) defend a kind of temporal instantiation relation, e.g. that a was $G .^{8}$ That is, a modified relation of instantiation is used to link particulars and properties. It strikes me that if it's plausible to accept a temporal instantiation tie, such as 'having-had' in addition to 'having', then it's plausible to accept a modal tie, such as 'possibly-having' in addition to 'actually-having'. The fact that something is possibly $G$, i.e. that something stands in a relation of modal instantiation, possibly-having, to some universal $G$, is a better truth-maker for truths about the (merely) possible instantiation of $G$ than the fact that nothing is $G$.

On this account, the distinction between a universal's being instantiated and being uninstantiated is preserved (in a sense) as a way of distinguishing alien properties (universals). Alien properties are those that stand in a modal instantiation relation ('possibly-having'), and never in the standard (actual) instantiation relation ('having'). But, most importantly, the actually existing truth-makers determining truths about possible instantiations of alien properties are positive facts. This will allow our platonist about possibility to resolve Tugby's alien paradox by denying Alienation (truths about alien properties aren't determined by what's actual), but without denying Positivity (everything that exists is positive). On this view, positive facts are at the heart of the platonist's story about what's possible, not any objectionable negative ontology.

Even so, it's worth reiterating that the alien paradox concerns alien propertiesthe paradox involves the demand for truth-makers that determine truths about possible instantiations of alien properties. Typically, an alien property is analysed as follows: a property, $F$, is alien if $F$ isn't instantiated at our world (Lewis 1983: 364; Armstrong 2004: 86-89; Tugby 2015: 30). Hence, in specifying what it is to be an alien property, there's negativity. And so truths about which properties are alien will be negative truths. One might reasonably object, at this stage, that any account of truth-makers for truths about alien properties will involve negativity. ${ }^{9}$ In the next section, I consider this anticipated objection in more detail and offer a principled reply.

\footnotetext{
${ }^{7}$ For the sake of simplicity, I ignore Barker and Jago's (2012) defence of a kind of anti-instantiation relation, e.g. that a isn't $G$, which they propose to try to rehabilitate negative facts. I think Barker \& Jago's proposal is a legitimate modification of the instantiation relation. But the connection with a proposed rehabilitation of negative facts would serve only to muddy the waters in this case. (Accepting the anti-instantiation relation, for instance, isn't viable for Tugby (or the platonist about possibility) since it requires denying Alienation and Positivity. Barker \& Jago don't accept Positivity; the rehabilitation of negative facts is an attempt to show that negative facts are as unobjectionable as positive facts.).

${ }^{8}$ This view is similar to one attributed to Mark Hinchliff by Lewis (1988); an 'adverbial' position, according to which 'temporal modifiers introduce relations of things to properties', incorporating the 'modified-having of a property' (1988: 66, fn. 2). See, also, the notion of 'tensing the copula' discussed by Lewis (2002).

${ }^{9} \mathrm{I}$ 'm grateful to an anonymous reviewer for suggesting this line of objection.
} 


\section{Alien Properties and Truth-makers}

Let's distinguish between two kinds of truths about alien properties. Then, I can clarify two distinct demands upon platonists regarding alien properties. Consider the following two propositions:

(P) That a might have been $F$.

(N) That nothing is actually $F$.

Suppose $F$ is the alien property, being megagon shaped (Tugby 2015: 30). Nothing actually instantiates being megagon shaped, but this property might have been instantiated by some particular, $a$. Hence, both propositions are true and each illustrates a different kind of truth (about alien properties). There are truths about the metaphysical possibility of alien properties being instantiated, e.g. (P); and there are truths about which properties are alien properties, e.g. $(\mathrm{N})$. Importantly, truths of the latter kind are straightforwardly negative truths, i.e. truths about what isn't the case.

With this distinction in mind, we can clarify two demands upon platonists. First, platonists are required to provide actually existing truth-makers that determine truths about possible instantiations of alien properties. (This is the crux of Tugby's 'alien paradox'.) I propose that platonists can satisfy the first demand, and resolve the alien paradox (conservatively), by stating that the actually existing truth-makers, determining truths about possible instantiations of alien properties, e.g. that a might have been $F$, are positive facts involving particulars standing in a relation ('possibly-having') to a property, e.g. the fact that a 'possibly-had' $F$. Hence, there's no need to appeal to any objectionable negative ontology in order to satisfy the first demand (and resolve the paradox).

But then there's the second demand: platonists must provide some account of which properties are alien, i.e. which properties aren't actually instantiated. Our anticipated objector might press this as a demand for truth-makers that determine truths about which properties are alien, e.g. that nothing is actually $F,(\mathrm{~N})$. So, we apparently require a truth-maker for the negative truth that nothing 'actually-has' $F$. But this is to demand truth-makers for negative truths, which strikes me as misguided. Further, note that no matter how many particulars stand in the modal instantiation relation ('possibly-having') to $F$, such (positive) facts about $F$ are together insufficient to determine that $F$ is an alien property. To guarantee that $F$ is alien, it must be that $F$ isn' $t$ instantiated in the standard way, i.e. nothing 'actuallyhas' $F$. Here we apparently require a further fact, determining that all the positive facts there are about particulars 'possibly-having' $F$ are all the facts there are about $G$. But such a fact is a totality fact and is undoubtedly negative (as above).

Well, why think negative truths have truth-makers? Maximalists (e.g. Armstrong 2004) think all truths have truth-makers, but many who are suspicious of negative ontology see no principled objection to restricting the class of truths that have truthmakers (cf. Melia 2005; Mumford 2005; Tallant 2010). Certainly, there's nothing that compels platonists about possibility to accept that negative truths require truthmakers. Platonists accept that truths about what's (merely) possible require existing truth-makers, i.e. positive facts involving particulars standing in the 'possibly- 
having' relation to properties, but don't need to accept that truths about what's not the case require truth-makers. And, further, since our platonism is intended to be conservative (in Tugby's sense), it's both intuitive and reasonable to suggest that negative truths are, as Lewis (1992) puts it, 'true not because things of some kind do exist, but rather because counterexamples don't exist' (1992: 216). More on this point, below.

At this stage, one might object that if we can reject a demand for truth-makers in the case of negative truths, then why can't platonists-who, typically, state that truths about possible instantiations of alien properties are made true by facts about universals not being instantiated-reject a demand for truth-makers in the case of truths about what's (merely) possible $?^{10}$ Or, put another way, why can't we state that truths about what's (merely) possible are just truths about what isn't the case (negative truths) and so don't require truth-makers?

My reply comes in two parts. The first part is primarily dialectical; the second involves a general and principled stance on restricting the truth-maker principle. To begin, recall that Tugby motivates the platonic theory of possibility by arguing that it solves the alien paradox. The modified version of the paradox, presented in this paper, comprises seven propositions:

1. It's true that instantiations of alien properties are metaphysically possible. (Possibility)

2. Truths about what's metaphysically possible have truth-makers. (Truth-maker)

3. Truth-makers determine their corresponding truths. (Determination)

4. All truth-makers exist. (Existence)

5. Everything that exists is actual. (Actualism)

6. Truths about alien properties aren't determined by what's actual. (Alienation)

7. Everything that exists is positive. (Positivity)

The important proposition here is (2), Truth-maker. There are truths about metaphysically possible instantiations of alien properties (e.g. that a might have been $F$ ) and, importantly, such truths require truth-makers. Tugby argues we shouldn't reject Truth-maker, to resolve the inconsistency, since it's a highly plausible claim, especially to philosophers of realist and actualist inclination (2015: 32). For Tugby, denying Truth-maker is less conservative than resolving the paradox by denying Alienation.

So far, I agree with Tugby. We shouldn't deny Truth-maker. But this stance doesn't generate any contradiction with denying that negative truths require truthmakers. Truth-maker is the proposition that truths about what's metaphysically possible require truth-makers; it's not the unrestricted (maximalist) claim "all truths require truth-makers." And, as suggested, I think we can deny the unrestricted claim. Denying that (e.g.) negative truths require truth-makers isn't equivalent to denying Truth-maker (and incurring a dialectical cost). Further argument is required

\footnotetext{
${ }^{10}$ Of course, this won't help Tugby. This is a distinct way to resolve inconsistency: denying Truth-maker (truths about what's metaphysically possible have truth-makers), rather than Alienation (truths about alien properties aren't determined by what's actual).
} 
to show that platonists (who accept modal instantiation) cannot consistently accept Truth-maker and deny that all truths require truth-makers. ${ }^{11}$

Let's consider Tugby's (2015: 32) motivation of Truth-maker; Tugby accepts maximalism and urges that we accept Truth-maker, since it follows from the more general principle. As Tugby puts it:

[Truth-maker] asserts that all truths about what is metaphysically possible have truthmakers, which is to say those truths are grounded in some aspect of reality. Anyone with realist intuitions will be inclined to agree, as do most of those engaging in the metaphysical debate with which we are concerned. The most straightforward reason for accepting this principle is that all truths have truthmakers. Armstrong calls this doctrine 'truthmaker maximalism' (2004: 5), and he urges all realist metaphysicians to accept it, because a serious metaphysics should not let truths 'hang on air' in a mysterious way (2004: 3). Moreover, to accept that some truths have truthmakers, while some do not, leaves us with a disunified metaphysics. ... And for the purposes of this article, it suffices to highlight that the denial of truthmaker maximalism is a significant theoretical cost for those in the business of realist metaphysics. (2015: 32)

Certainly, the most straightforward reason to accept Truth-maker is that it follows from maximalism. But why think maximalism is true? Why accept that all truths require truth-makers? Tugby gives two reasons to prefer maximalism to the alternative. First, if some truths don't require truth-makers, then such truths 'hang on air' (Armstrong 2004: 3) or 'float free' of reality. And, as Karen Bennett (2011: 187) points out, 'that's the kind of thought that leads to berets, and a job in a bad Comp Lit department'. Second, if some truths require truth-makers and other don't, then we have a 'disunified metaphysics'. Tugby urges, at the very least, denying maximalism is a significant theoretical cost.

The sorts of considerations adumbrated by Tugby give us reason to be suspicious of unmotivated and unprincipled restrictions on the class of truths that require truthmakers. But there are principled ways to restrict the class of truths that require truthmakers. In particular, it strikes me as entirely plausible that truths about what is the case require truth-makers, whereas truths about what isn't the case don't require truth-makers. Consider, for instance, the following from Melia (2005):

It is simply wrong-headed to think that there should be a truthmaker which corresponds to negative existential sentences. Intuitively, what makes a sentence such as 'There are no $F \mathrm{~s}$ ' is a lack of $F \mathrm{~s}$. ... [It] is just confused to think that we must account for a lack by postulating the existence of something else ... Such truths are truths because certain things don't exist, and it is wrong to try and understand this in terms of the existence of something new (2005: 69)

\footnotetext{
11 A brief aside: if we accept that denying Truth-maker is worse, all things considered, than denying Alienation, we should prefer a modal instantiation solution (to denying that truths about what's possible require truth-makers). As noted, Tugby's solution involves denying both Alienation and Positivity. Hence, Tugby's solution is less conservative (all things considered) than both other solutions described, i.e. denying one of either Truth-maker or Alienation. From a dialectical perspective, platonists about possibility should respond to the alien paradox by accepting the modal instantiation tie solution: denying Alienation, but accepting Truth-maker, Positivity, etc.
} 
One principled restriction: truths about what there is require the existence of something to determine their truth (i.e. a truth-maker), but truths about what there isn't require no truth-makers. Negative truths just aren't the sort of truths that require truth-makers (cf. Lewis 1992: 216; Merricks 2007: 64). Denying that negative truths require truth-makers doesn't result in a significant cost.

Platonists about possibility (who accept modal instantiation) can accept Truthmaker, but consistently deny that negative truths require truth-makers. There are good reasons for denying that negative truths require truth-makers (without implying that other truths, e.g. truths about what's (merely) possible, don't require truth-makers). On my view, platonists can provide truth-makers that determine truths about possible instantiations of alien properties. The truth-makers are positive facts: facts involving particulars standing in a modal relation ('possibly-having') to properties (universals). And, moreover, platonists have an account of which properties are the alien properties that doesn't require a commitment to objectionable negative ontology.

\section{Universals and Potential}

The main challenge in this paper is that Tugby's platonist about possibility fails to provide positive truth-makers that determine truths about possible instantiations of alien properties. That is, Tugby's truth-makers for truths about what's merely possible (including possible instantiations of alien properties) are facts about universals being uninstantiated, and such facts are negative. Even so, some of Tugby's remarks about the nature of universals suggest another way of thinking about what determines truths about what's possible. ${ }^{12}$ In what remains, I briefly consider this alternative view and motivate my preferred platonist account involving modal instantiation.

To begin, let's consider some important remarks from Tugby on the platonic theory of possibility and the nature of universals. Here I quote Tugby (2015) at length:

Suppose we accept that there are actual platonic universals and that at least some of them are uninstantiated. Is there not still the further question of whether it is possible for those universals to be instantiated? If the claim that some alien property instantiations are possible amounts to the claim that some platonic universals could have been instantiated, do we not need further facts to dictate precisely which uninstantiated universals can possibly be instantiated and which cannot? If these further facts are needed, then the platonist account is incomplete. Worst still, if those extra facts are primitive modal facts, then the platonist has not made much progress in illuminating modality. ... The answer is that the notion of a universal which cannot possibly be instantiated is incoherent. In other words, the mere existence of a universal guarantees that it is instantiable, which is to say that it is metaphysically

\footnotetext{
12 I'm grateful to two anonymous reviewers for pressing me on this point.
} 
possible for it to be instantiated. Why think this? The reason is that what it means for an entity to be a universal is precisely that it be instantiable in more than one place: this is where its universality lies. This is to say, in other words, that universals are repeatables. Quite simply, if an entity did not have the potential to be exemplified by multiple particulars, then it would not be a repeatable, in which case we would have no reason to class it as a universal as opposed to some other kind of entity. (2015: 35)

According to Tugby, a universal is a repeatable entity, which by its very nature has the potential to be multiply instantiated. The mere existence of a universal, $F$, implies that it's possible something is $F$. And so on for all universals.

This suggests another account of truth-makers for truths about possible instantiations of alien properties (and truths about what's merely possible, more generally) available to platonists, given in terms of only positive facts. Put simply, the truth-makers for truths about what's merely possible are positive facts about the mere existence of universals.

Consider the alien property, $F$. Nothing instantiates $F$, since it's alien. But something might have instantiated it. On the anticipated view, the truth-maker for the truth that a might have been $F$ is just the fact that $F$ exists. Plausibly, this fact determines the truth that a might have been $F$, since it's part of the nature the universal $F$ to have the potential to be instantiated by something. By contrast, consider a non-alien property, $H$. Let's suppose that $a$ is $H$; indeed, something must instantiate $H$, since it's non-alien. Here the truth-maker for the truth that a is $H$ is (simply) the fact that a is $H$. Similarly, the fact that $a$ is $H$ will also function as the truth-maker for the truth that a might have been $H$, since if $a$ is $H$ then it follows that $a$ might have been $H$.

In all relevant cases, truths (about possible instantiations) are made true by positive facts. But truths about what's merely possible are made true by facts about the existence of universals, not facts about that universal being (un)instantiated. This is the crux of the anticipated, alternative view. In what remains, I argue that this view fails as a way for platonists to resolve the alien paradox.

Let's return to the modified alien paradox. To resolve the inconsistency, platonists must provide actually existing positive truth-makers that determine truths about possible instantiations of alien properties. On the alternative view, presented above, the truth-maker that determines the truth of (e.g.) that a might have been $F$ is the positive fact that $F$ exists. But this fact isn't a suitable truth-maker for the truth that a might have been $F$. It isn't a suitable truth-maker since it doesn't necessitate the truth that a might have been $F .^{13}$ The fact that $F$ exists is compossible with the fact that $a$ is $F$ (and so consistent with the truth that $a$ is $F$ ). And, as such, facts about the mere existence of universals don't fully determine truths about what's merely possible.

\footnotetext{
13 Typically, the truth-making relation is characterised as a relation of 'cross-categorial necessitation' (Armstrong, 2004: 5-7), although isn't merely a relation of necessitation. A truth-maker is an entity, $e$, that necessitates the truth of a proposition, $p$. If $e$ necessitates the truth of $p$, then at all worlds in which $e$ exists $p$ is true. The fact that $F$ exists doesn't necessitate the truth that a might have been $F$, since the fact (that $F$ exists) can exist at worlds where it's false that a might have been $F$ (and, instead, true that a is F).
} 
According to platonists about possibility (who accept modal instantiation) the truth-maker for the truth that a might have been $F$ is the positive fact that a 'possibly-has' $F$. The existence of this fact (that a 'possibly-has' $F$ ) isn't compossible with the fact that $a$ 'actually-has' $F$, and so the fact that $a$ 'possibly-has' $F$ isn't consistent with the truth that a is $F$. By accepting the modal instantiation solution, platonists can provide truth-makers that necessitate their truths. This is a reason to prefer modal instantiation.

In conclusion, platonists about possibility, e.g. Bigelow and Pargetter (1990), Forrest (1986), and Tugby (2015), who are committed to the notion of a property being uninstantiated doing some theoretical work, and who share in the general dissatisfaction with positing any negative ontology, can benefit from accepting the proposed modal instantiation relation. ${ }^{14}$

Open Access This article is distributed under the terms of the Creative Commons Attribution 4.0 International License (http://creativecommons.org/licenses/by/4.0/), which permits unrestricted use, distribution, and reproduction in any medium, provided you give appropriate credit to the original author(s) and the source, provide a link to the Creative Commons license, and indicate if changes were made.

\section{References}

Armstrong, D. (1989). A combinatorial theory of possibility. Cambridge: Cambridge University Press. Armstrong, D. (1997). A world of states of affairs. Cambridge: Cambridge University Press.

Armstrong, D. (2004). Truth and truthmakers. Cambridge: Cambridge University Press.

Barker, S., \& Jago, M. (2012). Being positive about negative facts. Philosophy and Phenomenological Research, 85, 117-138.

Bennett, K. (2011). Truthmaking and case-making. Philosophy and Phenomenological Research, 83, $187-195$.

Bigelow, J., \& Pargetter, R. (1990). Science and necessity. Cambridge: Cambridge University Press.

Chalmers, D. (1995). The conscious mind. Oxford: Oxford University Press.

Dodd, J. (2007). Negative truths and truthmaker principles. Synthese, 156, 383-401.

Forrest, P. (1986). Ways worlds could be. Australasian Journal of Philosophy, 64, 15-24.

Lewis, D. (1983). New work for a theory of universals. Australasian Journal of Philosophy, 61, 343-377.

Lewis, D. (1986). On the plurality of worlds. Oxford: Blackwell.

Lewis, D. (1988). Rearrangements of particles: reply to Lowe. Analysis, 48, 65-72.

Lewis, D. (1992). Critical notice: Armstrong (1989). Australasian Journal of Philosophy, 70, 211-227.

Lewis, D. (2002). Tensing the copula. Mind, 111, 1-13.

McKinnon, N., \& Bigelow, J. (2012). Presentism, and speaking of the dead. Philosophical Studies, 160, $253-263$.

Melia, J. (2005). Truthmaking without truthmakers. In H. Beebee \& J. Dodd (Eds.), Truthmakers: The contemporary debate (pp. 67-84). Oxford: Oxford University Press.

Merricks, T. (2007). Truth and ontology. Oxford: Oxford University Press.

Molnar, G. (2000). Truthmakers for negative truths. Australasian Journal of Philosophy, 78, 72-86.

Mumford, S. (2005). The true and the false. Australasian Journal of Philosophy, 83, 263-269.

Mumford, S. (2007). Negative truth and falsehood. Proceedings of the Aristotelian Society, 107, 45-71.

Russell, B. (1989). Logic and knowledge. London: Routledge.

Schaffer, J. (2008). Truthmaker commitments. Philosophical Studies, 141, 7-19.

Tallant, J. (2010). There's no existent like 'no existence' like no existent I know. Philosophical Studies, $148,387-400$.

Tugby, M. (2015). The alien paradox. Analysis, 75, 28-37.

$\overline{14}$ I'm very grateful to Jonathan Tallant, Matt Tugby, and two anonymous reviewers for helpful feedback. 